\title{
A Preliminary Study about Solid Waste Caused by the Sudden Environmental Pollution Emergency System
}

\author{
Li-Ping $\mathrm{ZHOU}^{1,2, a, *}$ \\ ${ }^{1}$ Huazhong University of Science and Technology, Wuhan, P. R. China \\ ${ }^{2}$ Jiyuan Vocational and Technical College, Henan, P. R. China \\ ajyzlp638@163.com \\ ${ }^{*}$ Corresponding author
}

\begin{abstract}
Keywords: Sudden Environmental Events, Pollution Emissions, Solid Waste, Emergency Disposal, The Early Warning Management, Legislation
\end{abstract}

\begin{abstract}
In environmental pollution, solid waste considerable loss to the environment, the industrial and agricultural production and social stability, the masses life brings the serious influence. But the solid waste pollution, and the problems caused by exposure to toxic chemicals currently has not been fully understood. Effective solution is difficult to obtain. What exactly is a solid waste, its pollution how to produce, how pollution after the emergency disposal, how to control the spread of the pollution situation, for the people, the loss of the state and society at least as far as possible, all these problems need to cause social enough attention and concern. At the same time, should be established by the national long-term consistent sudden pollution incident early warning management system and legislation system. Article expounds solid waste pollution events, and of hazardous solid waste in us emergency treatment method, the improvement of the early warning management system and related laws and regulations of our country, put forward the proposal.
\end{abstract}

\section{Introduction}

Solid waste is what we call the garbage, it is the human metabolic waste and discarded items after consumption of consumer goods. Hazardous waste is to point to all of the harmful substances or can produce serious threat to the human body or the environment of solid waste. Because into dangerous solid waste material difference is very big, so you can according to the harmful ingredients of waste solid waste subdivided into subgroups, such as acid and alkali, heavy metals, reactive substances, solvents, and synthetic chemicals such as pesticides.

Despite toxic and hazardous substances in some production activities is indispensable. Normally, after entering the waste stream, dangerous substances is the production of useful features cause harm to the society. Waste streams is started in the waste, and transportation, storage, including waste treatment and disposal of a series of activities. Once the hazardous materials into the waste stream, due to overproduction and improper management of solid waste can produce environmental and health risks.

Toxic substances found in recent years, due to the leakage, the government asked people to be evacuated and malls official orders, which makes people to thrilled by the potential risk of solid waste pollution. Building basement, send out a strange smell, the contaminated water or doctors couldn't diagnose the disease symptom of autumn many aspects such as reports, these phenomena are accidental leakage or many years ago and waste buried some waste. In America, for example, 
because of the effect of poisonous and hazardous waste, the United States a lot of once very prosperous community, such as the New York of LAFU canal times beach, New York and Missouri have become ruins. These events and many of the awakening of solid waste pollution and exposure to toxic chemicals awareness of potential risks.

In the history of world environment pollution.It is well-known that LAFU canal community residents was caused by chemical solid waste.The LAFU canal community's home for 30 years ago, was once a huge chemical waste dumps, finally, President carter announced LAFU canal for the disaster area. Again, for example, in 1982, the state of Missouri times beach residents learned of their community in the groundwater and soil contains dangerous high levels of oxygen (hybrid) his second, and this is eleven years ago the area used by the pollution of asphalt as a result, therefore The Times beach residents evacuated.

The environmental pollution event sources are solid wastes from many years ago. The risk of solid waste is not sensational, but should cause enough emphasis on social and national policy makers, stacking and fully recycling of solid waste, strengthen the pollution source management, the previous year to reduce and eliminate the harm to people and future generations, this to the whole country, the whole world is a piece of art is the cause that nots allow to ignore.

\section{The Degree Of Pollution By Solid Waste}

Current urban residents living garbage and commercial waste, municipal waste generated in the maintenance and management, and industrial production and discharge of solid waste, the number has increased dramatically, composition is increasingly complex, far more than self-purification ability of nature. Deeply buried or the discharge of wastes, the poor management will produce harm to human health and ecology, and some harm even cannot be redeemed. A lot of living garbage produced continuously, with millions of tons of bottles, cans, garbage, etc., while the harm of waste is relatively small, but also have to pay attention. Many environmental hazards can endanger the waste all environmental media.

Industrial production and discharge of solid waste, the number has increased dramatically, composition is increasingly complex, far more than self-purification ability of nature. Deeply buried or the discharge of wastes, the poor management will produce harm to human health and ecology, and some harm even cannot be redeemed. A lot of living garbage produced continuously, with millions of tons of bottles, cans, garbage, etc., while the harm of waste is relatively small, but also have to pay attention. Many environmental hazards can endanger the waste all environmental media.

All environmental media, including air, soil, groundwater $r$ and surface water, are vulnerable to hazardous waste pollution. Potential hazards of the hazardous wastes including Marine pollution, soil pollution, disease, fish and livestock deaths. Hazardous waste is the enrichment of organisms in the environment of persistent pollutants, such as polychlorinated biphenyl (PCB) and dichloro diphenyl cross-linked with b (DDT), to human health and ecological cause serious and long-term impact.

The current all countries in the world is facing the risks of hazardous waste accumulation, for example, the United States produces about 173 million hazardous waste each year, the average per person per year to produce 0.66 tons of hazardous waste; Italy produced 2.7 million tons of hazardous waste per person per year, per capita 0.04 tons; Mexico each year about 8 million tons of hazardous waste per capita 0.10 tons. Due to the speeding up of industrialization, the third world countries also have a hazardous waste problems. At the same time, the developing countries must also deal with hazardous waste across the border to transfer problem, some enterprises in developed 
countries to avoid high cost of disposal of hazardous wastes and their strict rules, to transfer hazardous waste to developing countries. Hazardous waste, therefore, is a worldwide problem, ignore it means to bear huge risk.

Because of the rain after flowing through the waste dumps pollutants into the potable water system. Waste dumps is also contaminate groundwater and surface water, the damage is very serious, sometimes irreparably. Similarly, waste dumps surrounding soil will also be contaminated. In the contaminated soil on the growth of the crops absorb pollutants, finally absorbed by the human and animal. People living in the vicinity of hazardous waste dumps are particularly vulnerable to damage, such as LAFU canal event is the most typical example.

\section{The Source of The Solid Waste}

Solid waste mainly includes urban solid waste, industrial solid waste and agricultural waste. Now people are aware of some of the solid waste sources include: white pollution, waste batteries, etc. Waste battery is all we can come into contact with one of the typical and common hazardous waste (but are not produced by residents used batteries, control scope). A grain of button batteries can make 600 tons of water undrinkable for drinking water (one life). Such as disused mobile phone again, Americans out about 130 million every year. This means that produces 65000 tons of toxic metals and other harmful to body waste. The United States in 2001 produced about 229.2 million tons of solid waste, an average of 4.4 pounds per person per day. According to the EPA estimates that each year about 250 million tons of hazardous waste generated -- a ton per person per year on average, while only $10 \%$ were safe disposal.

\section{The hazardous solid waste source condition of American}

In America, for example, 99\% of industrial hazardous wastes from hazardous waste produced every month more than 2200 pounds of pollution sources, specific to see the table below:

Table 1 The major industrial hazardous waste

\begin{tabular}{|c|c|c|c|}
\hline Industrial & $\begin{array}{c}\text { The percentage } \\
\text { of hazardous waste }\end{array}$ & Industrial & $\begin{array}{c}\text { The percentage } \\
\text { of hazardous waste }\end{array}$ \\
\hline Chemicals & 79.0 & $\begin{array}{c}\text { Metal rough } \\
\text { machining }\end{array}$ & 1.0 \\
\hline Oil refineries & 7.0 & $\begin{array}{c}\text { Electrical } \\
\text { equipment }\end{array}$ & 0.4 \\
\hline $\begin{array}{c}\text { The transport } \\
\text { devices }\end{array}$ & 1.0 & National security & 0.4 \\
\hline Metal products & 1.0 & other & 9.0 \\
\hline
\end{tabular}

U.S.EPA(August 1988),P80,From U.S.EPA,Office of Solid Waste(n.d.).

From the above information as you can see, in the United States most hazardous waste from the chemical and petroleum industry, which accounts for $79 \%$ of the former.

\section{The solid waste source condition in China}

According to a 2005 survey report, according to data from China's solid pollution sources include industrial waste, urban waste and agricultural waste. With the development of economy, waste emissions increased year by year. 
About $95 \%$ of China's industrial solid waste from the following industries: mining, electricity, steam, hot water production and supply industry black metal smelting and rolling processing industry, chemical industry, non-ferrous metal smelting and rolling processing industry, food and beverage and tobacco manufacturing industry, building materials and other non-metallic mineral industry, machinery, electrical equipment manufacturing.

At present China's industrial solid waste composition is as follows: roughly tailings $29 \%$, and $19 \%$ of fly ash, coal gangue, $17 \% 12 \%$ slag, metallurgical slag, $11 \%, 10 \%$, other waste hazardous waste by $1.5 \%, 0.3 \%$ radioactive waste.

\section{City life solid waste}

City life solid waste is mainly refers to in daily life or for urban daily life in the city solid waste generated in the activities of the services they offer, namely urban living garbage, mainly including residents living garbage, hospital waste and commercial waste, building waste (also called waste residue). Generally speaking, the city per day increase there is $1 \sim 2 \mathrm{~kg}$, its composition and people material life level more and less, habits, degree of waste materials recycling, municipal construction, etc. Light from city life solid waste, discharge of every year is very alarming. In general, city life level is higher, the greater the garbage output. Cities in low-income countries, such as Calcutta, Karachi and Jakarta, waste generated 0.50 .6 kilograms per person a day, the big cities in middle-income countries, the figure is 0.5 to $0.8 \mathrm{~kg}$, big cities in the industrialized countries, waste generated in the usually around $1 \mathrm{~kg}$ per person a day. Latest statistics show that the developed countries daily life garbage output is as high as $1.5 \mathrm{~kg}$ per person. Garbage is the product of human activity. People enjoying the food and clothing live line at the same time the living garbage, while social need products produced industrial waste.

\section{Agricultural waste}

Agricultural production, agricultural products processing, livestock and poultry breeding industry and rural residents living the floorboard of the discharge of wastes. It mainly includes the farmland and orchard residues (such as straw, grass, leaves, etc.), livestock and poultry excrement and corral bedding, agricultural products processing waste and sewage, human waste and waste of life, mainly on organic matter. If any emissions not only caused the rural living environment pollution, and agricultural water pollution, affecting the quality of agricultural products, agricultural production.

In this global village with a population of more than 60 , we have no so many places to pile the solid wastes, and be intolerant of disease and poverty they bring to us. We should use the continuous development of advanced science and technology, along with the perfect environmental legislation, to minimize the generation of solid waste, make its can be recycled as far as possible, as much as possible to deal with solid waste, prevent and control risk, and risk control in the lowest.

\section{Sudden Environmental Incidents Emergency System In Our Country The Status Quo}

At present, our country's current deal with the emergency environmental accidents mainly embodied in the constitution and the law of the environmental protection law, at the same time a large number of referring to the relevant laws and regulations of line. So far, our country has not a special law to regulate. But in reality, this kind of setting and the legislative status quo of the legal system, already cannot satisfy the need of society, has exposed many malpractices. Specific performance is as follows:

\section{The constitution and constitutional law relevant provision shortcomings}

The constitution and the constitutional law related defects and deficiencies in the following aspects: first, from the perspective of the history of development of the People's Republic of China 
reality and in abrupt environment affairs ring of emergency laws often appear, but the current constitution is focus on the normal order of the constitutional issues, including the emergency environmental accidents emergency response system, our country has not integrated the basic law, is only related to the state of emergency "martial law" in 1996, the law's provisions clearly unsuitable for emergency environmental accidents emergency response. Second, clearly stipulated in the constitution of our country "national protection and improvement of the living environment and ecological environment, prevent and control pollution and other public hazards" and other relevant provisions, but did not specify the citizens shall enjoy the right of environment is a basic right. Anyone "without property of other people to use their own property rights. The integrity of the environment and determine the public quality of environmental right, and when the citizen's environmental right is a violation, the victim is hard from the constitution on the national law to seek legal basis and the basic rights.

\section{Emergency environmental accidents emergency system lack of separate legal entities}

In current environmental law and special law made some rules to deal with the emergency environmental accidents, such as the Marine environmental protection law, the law on the prevention and control of water pollution, the law on the prevention and control of atmospheric pollution, the law on the prevention and control of radioactive pollution, etc., were hit for emergency treatment measures, however, first of all, the lack of systemic; Second, the lack of completeness; Thirdly, the author thinks that reducing the authority, thus affect the legal effect.

\section{The information disclosure system is not sound}

Information disclosure is an important performance of civil environment right. After the emergency environmental accidents occur, often related to important information not timely, accurate, comprehensive reflection to the competent authority, submits, slow, conceal phenomenon emerge in endlessly, important information is neglected, the value of information cannot be open, more what about citizens' right to know the problem. The songhua river water pollution incident, the general public of Harbin is still clearly remember the government initially issued notice "network maintenance, water cut off four days", the media also subsequently echo, the government led by information confidential, and how to be accuracy! Information of fraud, make originally very valuable information resources, artificially reduce or even lose its value, civil rights virtually had been deprived of, this is the sad province of our country under the rule of law. The struggle for rights, urgent!

\section{Civil participation is difficult to effective implementation}

The our country present law of civil participation is too general and abstract, as previously mentioned, citizen's environmental right and the right to know, there is no law to specify or to ensure proper implementation. This is both good for citizens exercise their rights, at the same time, reflects the social democracy and legal system construction to the environment in our country the concept of indifference. Therefore, the laws and regulations about civil participation, its actual effect is restricted by the law.

\section{The lack of professional, unity and powerful emergency organization management institutions}

At present, in the whole country public emergency contingency plans specified in the leadership of the state council is the highest administrative emergency management agency. After the occurrence of abrupt environment affairs, however, its emergency handling organization, mostly temporary team combination is reactive, lack of professionalism and unity, nobody is unknown, 
both restricted the emergency event handling control ability, may also virtually the expansion of public interest sex. And as defenders of the public interest and the server, such institutions really hard to accept the drawbacks.

\section{There are serious shortcomings on the legal liability provisions}

Right and compulsory phase is unified, consistent right is a fundamental principle of jurisprudence. Legal liability principle, we emphasized, cannot let no illegal people assume legal responsibility, namely against collective punishment or disguised collective punishment; To ensure that those responsible shall be investigated by the law, shall be immune from legal is also to ensure that no responsible, namely, do not waste. (4) and the our country present legal liability provisions, that is not clear, unfair distribution, the pursue is unreasonable, this undoubtedly become one of subjective indulgence emergency environmental accidents frequently happen.

\section{The Hazardous Solid Waste Early Warning Management System For The Enlightenment Of Our Country}

The United States in 1976 issued the act of resource conservation and reuse. According to the classification in the act of resource conservation and reuse, here refers to hazardous waste is not an absolute sense of harmful, but according to the discharge of hazardous waste decide the degree of "bad" and "harmless" there is no absolute meaning. The bill of resources protection and utilization of hazardous waste is divided into two kinds, characteristic of waste and waste list. Based on the theory study in the United States, set up the hazardous waste tracking system, the super fund project (the comprehensive environmental response, compensation and liability act) and return the deposit system.

The sudden environmental pollution emergency system in our country, as well as the many kinds of malpractice of exposure, fully shows the sudden environmental emergency response system in China needs to be improved and perfected, so as to adapt to the current situation of urgent need.

\section{To develop the emergency law, environmental right into constitution}

The main constitution, the most core value is that it is the guarantee of civil rights. Environmental rights into the constitution, it is in the perfection of legal system on human rights in our country, is also the national environmental protection concepts is an important symbol of sublimation. As a fundamental right of citizen, not only to set forth from the entity, but also should be given security on the program, we are opposed to program to program, but the lack of necessary procedures to ensure the substantive rights of basically is difficult to achieve. To improve the environment protection act in legal status in the environmental legislation system, must be in legislation, general environmental protection law of the status of ascension to be formulated by the National People's Congress (NPC), and rise to the basic law of environment. Make it really become guide other environmental laws and regulations of basic legal line. An urgent need to formulate a "emergency law", to guide the different types of emergency special laws and regulations in our country.

\section{Establishing and perfecting environmental emergency notification and reporting system}

Environmental emergency notification and reporting system, is to actually is closely related to environmental emergencies the true information of the transmission system. After the evaluation of the impact of several aspects, such as there are serious drawbacks. In the songhua river water pollution event ", said, "in the event of emergency handling process, fully embodies the Chinese emergency government crisis management system has defects, fragmented, with obvious color 
department management.

\section{A sound system of public participation}

Wide public participation is the important way to safeguard their legal rights and interests, participation is the premise of the public must have a good psychology to bear ability and crisis prevention and emergency response, and so on common sense. A polluted river, people tried to rob to buy the water for food, which reflects the public psychology to bear ability weak question, as well as crisis emergency a lack of common sense. Therefore, strengthening emergency knowledge education, cultivation of crisis consciousness is particularly important to give full play to the power of the public, in reality materialize, the crisis in the bud.

\section{Building strong full-time government crisis management mechanism}

The current our country has preliminarily established crisis management mechanism, but emergency environmental accidents in China and its emergency treatment process, the subject of emergency management institutions set up is still can not accept. Today, many countries have set up special crisis management institutions, such as the us federal emergency management agency (FEMA), the cabinet crisis management center, etc., and, of course, our country should be according to the need to set up a specialized agency for crisis emergency management. Interests as the basis, with numerous people to represent the fundamental interests of most people, serve the people, to establish a clear organization capable, responsibilities, scientific decision-making, action quick strong specialized agencies to achieve the above purpose.

\section{strengthen the management of solid waste collection, set up special solid waste collection agencies}

The construction of perfect community recovery system, speed up the construction of improving the recycling system. Renewable resources recovery is the basis of the comprehensive utilization of renewable resources and protection. Science recycling network layout, speed up the integration and standardize the existing resources, to promote community recycling network construction. Give priority to with mobile site, timing, fixed point, a person is adopted to improve the recovery. Flow site combined with fixed site, conditional community recycling of setting up the site. Recycling site Settings must follow the principle of convenient, in the traffic and noise, environment, etc, to avoid a nuisance. On the mode of operation in each area recycling companies set up recycling in community site as the main body, property, residents' committees and other patterns.

The construction of dedicated recycling channels, improve the efficiency of recycling. Because of waste household appliances, automobiles, household garbage and the nature characteristics of hazardous waste, can not completely rely on community recycling outlets, need to build dedicated recycling channels, and explore the producer responsibility system, further standardize between manufacturers, distributors, consumers and the recycling of responsibilities and obligations. Professional of hazardous waste collection, for example, to establish regional scrapped automobiles, batteries, and solid waste recycling network. Reduce circulation, reduce the range of pollution damage, and increases the acquisition and transfer of the enthusiasm.

\section{Establishing emergency rescue system}

In the face of sudden environment pollution accident, should not only solve the emergency monitoring and treatment, disposal, and implement emergency rescue and aftermath settlement, to minimize the harm of the pollution accident. Emphasize here that once after the sudden environmental pollution incidents, here because the time is limited, the processing of the 
importance of life and property safety, so it is not only the environmental protection department, but should be a state of emergency. For example, in 1977 the United States to pull wu canal incident, cartel's President has ordered the canal community as "disaster area".

Handling matters as follows: (1) to organize the implementation of environmental recovery plan; (2) monitoring and evaluating environmental pollution condition, until the basic recovery; (3) when necessary, the long-term impact of people and animals and plants monitoring; (4) to evaluate pollution loss, coordinate to deal with pollution compensation and other matters.

Pollution accident is not only to the local people's life, body health caused great influence, add a big workload and pressure to the environmental protection department, but also bring social stability and instability, is what people don't want to see (include a company), so the pollution accident should first do nip in the bud.

The whole society to carry out the environmental quality and emergency disposal of education, school courses in the environmental quality education

Wake-up call for environmental protection, the whole society every citizen should serve as a environment protection volunteer, start from the self, and stop to prevent pollution of the environment consciousness and behavior. For sudden environmental pollution incident, we must learn how to emergency disposal, and also do to protect themselves, as far as possible to reduce the loss to the minimum. American from primary school opened the course "environmental quality education" is deeply rooted in the hearts of the people environmental protection consciousness is closely connected with the practice of positive significance.

\section{References:}

[1] She Lian, On Enterprise Forewarning Management, Hebei Science and Technology Press, 1999

[2] Lan Zhilong, Sun Chunxia, American Public Policy in Action, Beijing:China Renmin University Press, 2007, 10:304-318

[3] Portney, Paul R.and Stavins Robert N.:Public Policies for Environmental Protection, Shanghai: Shanghai Joint Publishing Company and Shanghai People's Publishing House (SPPH), 2004

[4] Ortolano, Leonard, Environmental Regulation and Impact Assessment, Beijing: Chemical Industry Press, 2004

[5] Department of Total Pollutants Control of State Environmental Protection Administration, Basel Convention on the Control of Transboundary Movements of Hazardous Wastes and Their Disposal.Beijing: Chemical Industry Press, 2002

[6] Zhang Yijun, A handbook of the United States government.Beijing: Military Publishing Hou se of Friendship and Literature, 2000 